\title{
Improvement of wheat productivity and soil quality by arbuscular mycorrhizal fungi is density- and moisture-dependent
}

\author{
Hai-Xia Duan ${ }^{1} \cdot$ Chong-Liang Luo ${ }^{1} \cdot$ Ji-Yuan $\mathrm{Li}^{1} \cdot$ Bao-Zhong Wang ${ }^{1} \cdot$ Minha Naseer ${ }^{1}$ - You-Cai Xiong ${ }^{1}$ \\ Accepted: 27 November 2020 / Published online: 7 January 2021 \\ (C) INRAE and Springer-Verlag France SAS, part of Springer Nature 2021
}

\begin{abstract}
Adaptive management of arbuscular mycorrhizal fungi (AMF) provides a new option for sustainable agriculture. Previous studies showed that the functional role of AMF was frequently dependent on soil moisture and planting densities in the semiarid environment. However, a systematic quantitative analysis of the effects of AMF inoculation on crop productivity and soil quality needs to be investigated. Therefore, a 2-year field experiment was conducted to test the inoculation effects of AMF (Funneliformis mosseae) on wheat (Triticum aestivum L.) productivity and soil quality in the semiarid Loess Plateau under two water regimes (irrigated and non-irrigated) with seven plant densities in year 2017 and 2018. Our results showed that in the non-irrigated treatment, inoculation with AMF greatly increased dryland wheat aboveground biomass, crop productivity, water use efficiency, rhizosphere soil organic carbon, soil organic carbon to total nitrogen ratio, microbial biomass carbon to nitrogen ratio, and microbial biomass carbon and nitrogen $(P<0.05)$ compared to the non-inoculated treatment. For example, compared with non-inoculated plants, the grain yield in the non-irrigated but inoculated plants increased by $59 \pm 28 \%$ in 2017 and $36 \pm$ $2.8 \%$ in 2018, and the water use efficiency for grain increased by $53 \pm 26 \%$ and $25 \pm 12 \%$ in 2017 and 2018, respectively. However, the different results were observed under irrigated conditions. In the irrigated treatment, AMF inoculation had a slightly positive effect on grain yield and soil quality at low plant density but was negative at higher plant densities. Here we demonstrated for the first time that AMF inoculation significantly improved wheat productivity and soil quality, while its effects were conditionally density- and moisture-dependent. Therefore, optimizing AMF addition is an effective measure for sustainable agricultural development and provides a novel solution for the management of soil degradation management in the semiarid area of the Loess Plateau.
\end{abstract}

Keywords Agroecology $\cdot$ Arbuscular mycorrhizal fungi $\cdot$ Soil nutrients $\cdot$ The Loess Plateau

\section{Introduction}

As drylands cover more than $40 \%$ of the world's land surface and are home to one-third of the global population, half of the inhabitants in the dryland depend directly on rainfed or irrigated farming (Farooq and Siddique 2016). Food insecurity, frequent droughts, environmental degradation, and biodiversity loss are widespread in these areas. Dryland agriculture is becoming increasingly important to global food security

Hai-Xia Duan and Chong-Liang Luo contributed equally to this work.

You-Cai Xiong

xiongyc@1zu.edu.cn

1 State Key Laboratory of Grassland Agro-ecosystems, Institute of Arid Agroecology, School of Life Sciences, Lanzhou University, Lanzhou 730000, China
(Farooq and Siddique 2016) and agroecosystem sustainability. However, meeting the challenge of increased food production should not preclude the implementation of more sustainable farming approaches in dryland areas (Wezel et al. 2014). Current trends in world agriculture show that it is imperative to find a scientific and rational way to steadily increase the crop yield, but also to ensure long-term sustainable use of soil resources while promoting agricultural development (Mo et al. 2020). Agroecological transition addresses the paramount challenge of feeding a growing population with scarce resources without compromising the environment (Wezel and Soldat 2009).

The Loess Plateau is the largest rainfed agricultural region in China. Wheat is one of the most important food crops on the Loess Plateau. Moreover, the low crop productivity in the agroecosystems of the Loess Plateau is largely due to poor soil fertility, inefficient rainwater use, and the frequency of 
drought (Mo et al. 2020). Water stress is one of the most ominous abiotic factors to restrain the productivity of crops in many regions of the world (Shukla et al. 2012), which is putting the sustainability of plant production and dry matter accumulation of crops at stake (Kahmen et al. 2015). In modern agriculture, farmers usually try to improve wheat yield through increased plant density. With increased planting density, the main factor limiting crop yield is the limited resources. Higher population density leads to stronger intraspecific competition that consumes more environmental resources that eventually will result in a decrease of grain yield and soil quality (Sui et al. 2019).

Soil organic matter is an important basic component in the terrestrial ecosystem, which determines the function and sustainability of the ecosystem (Koch et al. 2004). Soil degradation, mainly featured by decreasing soil organic carbon, may further accelerate a decrease in field productivity. Thus, soil organic carbon and total nitrogen have gained greater attention. Maintenance of soil quality and crop yield relies on the functioning of soil microorganisms for soil organic matter decomposition, residue degradation, and nutrient transformations (Crouzet et al. 2016). Microbial biomass not only serves as a medium for the decomposition of soil organic matter but also determines the nutrient pool available to plants in the soil (Hargreaves et al. 2003; Ren et al. 2020). The rhizosphere is the soil layer affected by plant roots and microorganisms that plays a key role in plant growth and soil quality.

Arbuscular mycorrhizal fungi (AMF) are relatively common plant symbiotic fungi, viewed as "microbial fertilizer" that are beneficial to crop growth and productivity (Zhang et al. 2016; Sui et al. 2019). There is increased recognition that mycorrhizal fungi can significantly influence soil organic matter decomposition and nutrient (especially nitrogen, $\mathrm{N}$ ) cycling (Bedini et al. 2009) that is a crucial aspect of sustainability in agriculture (Wezel et al. 2014). AMF are generally found to have positive effects on host plant growth and soil quality, but intensive agricultural management practices are often considered to reduce mycorrhizal function (Thirkell et al. 2017). High nutrient availability from chemical fertilizers, high soil moisture, and disturbance may reduce the role of mycorrhizas to neutral symbionts (Trejo et al. 2016) or even to pathogens/parasites (Dai et al. 2014). Such a pattern may confound the application of AMF inoculation in agriculture. Therefore, more studies are needed to clarify how plant production and soil organic matter decomposition differ in their responses to environmental stress with AMF inoculation. Importantly, exploring the response of the soil carbon and nitrogen pool to AMF inoculation is crucial to evaluating the effects of AMF usage on soil quality and agricultural sustainability development in the semiarid areas.

The objective of this study was to investigate the effects of allochthonous AM fungus on the diversity of native AM fungal community, dryland wheat grain yield, aboveground biomass, harvest index, water use efficiency, rhizosphere soil quality, microbial biomass carbon, and nitrogen content under different plant densities and water regimes in the field on the semiarid Loess Plateau of China (Fig. 1). The following questions were addressed: (1) Does inoculation with AMF have effects on the AMF community? (2) What is the effect of inoculation with an AM fungus on dryland wheat grain yield under density and drought stress? (3) What is the effect of inoculation with an AM fungus on soil quality? And do positive effects of the AMF differ when the crops are subjected to drought stress and different plant densities? We hypothesized the following: (i) Exogenous AMF would be successfully colonized in rhizosphere soil and affect the native AMF community composition. (ii) AMF inoculation would significantly increase wheat productivity and soil quality, and (iii) the effects of AMF are density- and moisture-dependent.

\section{Materials and methods}

\subsection{Experimental design}

The field experiment was conducted at the Yuzhong Experiment Station of Lanzhou University in Yuzhong County, Gansu Province, China ( $35^{\circ} 51^{\prime} \mathrm{N}, 104^{\circ} 07^{\prime} \mathrm{E}$, altitude $1620 \mathrm{~m}$ ), over two growing seasons (April-July) from 2017 to 2018. Conditions were kept similar throughout the both experiments. The 2018 experiment is carried out on the same plots as the 2017 experiment. The site has a semiarid climate, typical of the gully region of the Loess Plateau with annual rainfall of $512 \mathrm{~mm}$ (long-term wheat growing season (April to July) rainfall $=150 \mathrm{~mm}$ ) and mean annual air temperature of $7.6^{\circ} \mathrm{C}$ (long-term wheat growing season temperature $=15.5^{\circ} \mathrm{C}$ ). In 2017 the growing season temperature was $15.8^{\circ} \mathrm{C}$, and rainfall was $156 \mathrm{~mm}$. In 2018 the growing season air temperature was $15.9{ }^{\circ} \mathrm{C}$, and growing season rainfall was $281 \mathrm{~mm}$. The experimental plot had been under long-term continuous cropping with spring wheat. The soil is predominantly clay textured according to the USDA texture classification system with a $\mathrm{pH}$ of 8.0 and bulk density of $1.20 \mathrm{~g} \mathrm{~cm}^{-3}$. The rhizosphere soil $(0-30 \mathrm{~cm})$ had the following physical and chemical properties at the beginning of the experiment in 2017: soil organic carbon $8.04 \mathrm{~g} \mathrm{~kg}^{-1}$, total soil nitrogen $0.82 \mathrm{~g} \mathrm{~kg}^{-1}$, soil microbial biomass carbon $64.5 \mathrm{mg} \mathrm{kg}^{-1}$, microbial biomass nitrogen $10.1 \mathrm{mg} \mathrm{kg}^{-1}$, and pH 8.04; and soil organic carbon $8.47 \mathrm{~g} \mathrm{~kg}^{-1}$, total soil nitrogen $0.86 \mathrm{~g} \mathrm{~kg}^{-1}$, soil microbial biomass carbon $85.5 \mathrm{mg} \mathrm{kg}^{-1}$, microbial biomass nitrogen $15.6 \mathrm{mg} \mathrm{kg}^{-1}$, and $\mathrm{pH} 8.01$ at the time of sowing in 2018.

In each year, a $2 \times 2 \times 7$ factorial experiment was conducted in a randomized complete block design with three replications. The study tested two inoculation treatments under irrigated and non-irrigated conditions to form four 
Fig. 1 Photographs of the field experiment in 2017 (a) and 2018 (b) and light micrographs of root colonization of wheat root in (c) non-AMF inoculation and (d) AMF-inoculated soil
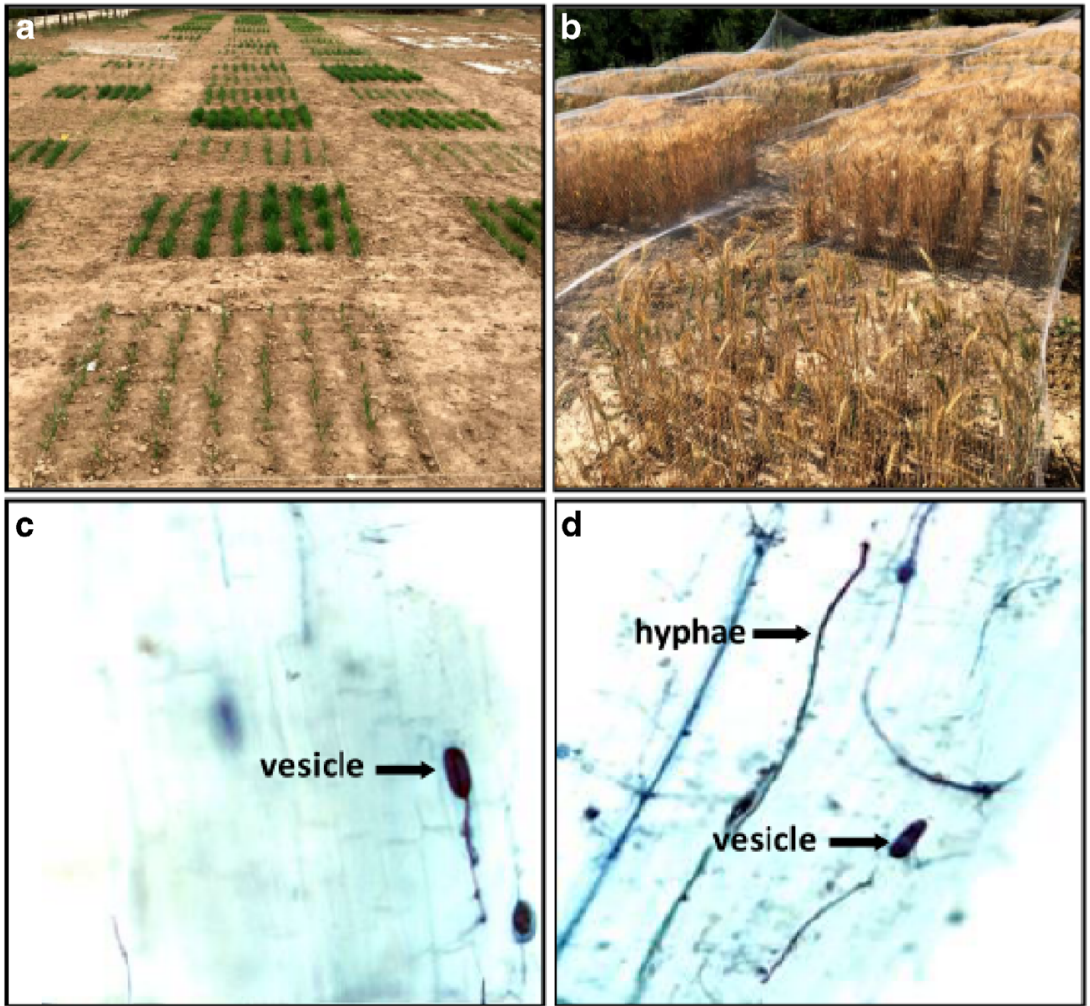

combinations: (1) irrigated and inoculated with AMF of Funneliformis mosseae ( WW + A), (2) irrigated and noninoculated (WW), (3) non-irrigated and inoculated with AMF of $F$. mosseae (WS + A), and (4) non-irrigated and non-inoculated (WS). In the irrigated treatments, the total amount of irrigation water was $120 \mathrm{~mm}$, supplied with three splits of 20,40 , and $60 \mathrm{~mm}$, respectively, at the tillering, jointing, and flowering stages in both growing seasons. There were 7 plant densities: 50, 100, 200, $400,800,1600$, and 3200 plants $\mathrm{m}^{-2}$ in both growing seasons. Each treatment plot was $1.5 \mathrm{~m} \times 1.5 \mathrm{~m}$ consisting of 7 rows spaced $0.2 \mathrm{~m}$ apart and $1.5 \mathrm{~m}$ long; a $1 \mathrm{~m}$ buffer zone was left between each plot. The distance between irrigated and non-irrigated treatments was $5 \mathrm{~m}$. Wheat was sown on 1 April 2017 and 3 April 2018 and harvested on 31 July 2017 and 1 August 2018, respectively. Each year, phosphate fertilizer and nitrogen fertilizer were applied once as a base fertilizer $\left(150 \mathrm{~kg} \mathrm{P} \mathrm{ha}^{-1}\right.$ and $225 \mathrm{~kg}$ $\mathrm{N}$ ha $^{-1}$ ) before seeding. The base fertilizer ( $\mathrm{N}$ and $\mathrm{P}$ ) was applied broadcast and incorporated with cultivation to the soil depth of $20 \mathrm{~cm}$ with a chisel plow $(20 \mathrm{~cm})$ equipped with sweeps (heavy-duty cultivator). No herbicides were applied during wheat growth.

\subsection{Plant material and growth conditions}

In this study, the modern spring-type wheat c.v. Longchun-29 with indehiscent awned ears and naked grains, released in
2009 and still widely grown on the Loess Plateau, was used. The crop growing season was approximately 120 days in both years.

The AMF species used in this study was Funneliformis mosseae (syn. Glomus mosseae) provided by the Institute of Agriculture, the University of Western Australia in 2015, and identified as an aggressive colonizer of wheat (Graham and Abbott 2000). The original spores used to start this culture were extracted from a black Vertisol from a farm near Macalister, Queensland, in 1990. Inoculum of F. mosseae was propagated with Trifolium repens L. in sterilized soil in the growth chamber for 4 months in 2016 and 2017. The density of spores in the inocula of $F$. mosseae estimated by microscopic examination after wet-sieving and centrifugation, to be 50-80 spores per $10 \mathrm{~g}$ of soil. For the AMF treatment, $F$. mosseae inoculum (667 $\mathrm{g} \mathrm{m}^{-2}$; containing spores, hyphae, and infected clover root fragments) was inoculated into the furrow while sowing (the inoculum was evenly applied into each furrow in all plots of AMF inoculation treatment).

\subsection{Plant biomass production and mycorrhizal colonization}

All the plants were harvested in each plot to measure the grain yield and aboveground biomass at the maturity stage (122 and 121 days after sowing in 2017 and 2018, respectively). The grain yield and the total aboveground biomass for each plot were air-dried naturally, to constant weight and weighed. The 
harvest index (HI) was calculated: harvest index = grain yield $/$ total aboveground biomass.

Root colonization levels were determined microscopically using the grid line intersect method (Giovannetti and Mosse 1980). This method uses a compound microscope (200 to $\times$ 400) to measure the percentage of root length colonized by hyphae, vesicles, hyphal coils, arbusculate coils, and arbuscules. Samples were taken from the fresh root systems of five plants per plot to assess mycorrhizal colonization. Roots were carefully washed, fine roots $(0.5 \mathrm{~g}$ fresh weight) were picked out by hand from the samples and cut into $1-\mathrm{cm}-$ long fragments, cleaned in $10 \% \mathrm{KOH}$, stained with $0.05 \%$ trypan blue for $3 \mathrm{~min}$, and destained in lactate-phenol solution, and then the root colonization was observed and recorded under the microscope (Giovannetti and Mosse 1980).

\subsection{Soil nutrients}

In each plot, three fresh soil samples of rhizosphere soil (0$30 \mathrm{~cm}$ ) were carefully separated from the roots using a fine nylon bristle brush and tweezers at the maturity stage in both growing seasons. The three samples were combined into one replicate sample; each treatment had three replicates. The visible plant residues were removed by hand and then passed through a 2-mm sieve to remove the plant roots. Each soil sample was divided into two parts: One part was naturally air-dried for analysis of soil organic carbon (SOC) and total nitrogen (TN), and the other part was sealed into airtight plastic bags and transported to the laboratory under lowtemperature conditions for analysis of the soil AMF community, soil microbial biomass carbon (MBC), microbial biomass nitrogen (MBN), and soil extra-matrical hyphal length $(\mathrm{EMH})$. SOC was determined by the potassium dichromateconcentrated sulfuric acid external heating oxidation method. TN was measured by the Kjeldahl method-automatic nitrogen analyzer (Beijing, China). The soil MBC and MBN were extracted via the chloroform fumigation extraction method (Brookes et al. 1985). EMH was measured as described by Jakobsen et al. (1992).

\subsection{Crop water consumption and water use efficiency}

Each plot was surrounded by high ridges to prevent runoff. We calculated crop water consumption (CWC) using the following formula: $\mathrm{CWC}=P+I+\Delta \mathrm{SWS}$, where $P(\mathrm{~mm})$ is the total rainfall during the growing season, $I(\mathrm{~mm})$ is the irrigation amount during the growing season, and $\Delta \mathrm{SWS}(\mathrm{mm})$ is the difference in soil water storage $(0-100 \mathrm{~cm})$ between the beginning and the end of each growing season. Water use efficiency for grain yield $\left(\mathrm{WUE}_{\mathrm{Y}}\right)$ and aboveground biomass $\left(\mathrm{WUE}_{\mathrm{B}}\right.$ ) was calculated as the ratio of grain and aboveground biomass to $\mathrm{CWC}$, respectively.

\subsection{AMF community analysis in the rhizosphere soil}

Total DNA from $0.5 \mathrm{~g}$ rhizosphere soil was extracted using the E.Z.N.A. Soil DNA Kit (OMEGA, Bio-Tek, USA) according to the manufacturer's protocols. The DNA was used as a template for nested PCR in AM fungal special primers. The first primer pair were AML1 and AML2, and the second primer pair were AMV4.5 NF and AMDGR. The second PCR products were obtained using the AxyPrep DNA Clean-up System kit (Axygen Scientific Inc., USA). Each sample was quantified using QuantiFluor TM-ST (Promega, USA), and the TruSeq TM DNA Sample Prep Kit (NEB, USA) was used to set up Miseq DNA library. The qualified samples were then loaded into an Illumina MiSeq platform, and the sequencing was performed by Majorbio, Shanghai, China. The detailed information was provided as previously described by Zhu et al. (2017).

\subsection{Data analysis}

Data were analyzed by three-way ANOVA (AMF, water treatments, and plant densities) using SPSS version 17.0 (SPSS Inc., Chicago, IL, USA). All univariate analyses were performed in SPSS version 17.0. The Tukey test values at $P \leq$ 0.05 are presented where significant effects were found. All the figures were made using Origin 8.5.

\section{Results and discussion}

\subsection{AM fungal root colonization rate and hyphal length of the rhizosphere soil}

Arbuscular mycorrhizal colonization levels in F. mosseae inoculated wheat were about $50.4 \pm 5.5 \%$ of root length on average, but $20.4 \pm 2.0 \%$ were observed in the non-mycorrhizal treatments, and AMF inoculation significantly improved the mycorrhizal root colonization rate of wheat (Table 1). Meanwhile, AMF inoculation significantly increased the hyphal length in the soil. These results indicated that exogenous $F$. mosseae had been successfully colonized in the wheat rhizosphere and acted effectively in the soil. Moreover, plant mycorrhizal root colonization rate increased in the nonirrigated treatment, that is, the WS + A treatment had a higher mycorrhizal colonization rate value than in the $\mathrm{WW}+\mathrm{A}$ treatment, especially at high plant densities, and mycorrhizal colonization rate in the WS was higher than the corresponding value in the WW (Table 1). In addition, increasing plant densities caused a significant decrease in AMF colonization rate (Table 1). Similarly, the hyphal length of soil had the same trend as the root colonization rate (Table 1).

AMF colonization rate was significantly affected by water availability and plant density; in most cases, the AMF 
Table 1 AMF colonization rate of wheat root (\%), soil extra-matrical AMF hyphal length $\left(\mathrm{m} \mathrm{g}^{-1}\right)$, aboveground biomass water use efficiency $\left(W_{U} E_{B}, \mathrm{~kg} \mathrm{ha}^{-1} \mathrm{~mm}^{-1}\right.$ ), and grain yield water use efficiency (WUE $\mathrm{kg} \mathrm{ha}^{-1} \mathrm{~mm}^{-1}$ ) of wheat over two growing seasons under different water regimes, AMF inoculations, and plant densities

\begin{tabular}{|c|c|c|c|c|c|c|c|c|c|}
\hline & \multirow[t]{2}{*}{ Year } & \multirow[t]{2}{*}{ Treatment } & \multicolumn{7}{|c|}{ Plant density (plants $\mathrm{m}^{-2}$ ) } \\
\hline & & & 50 & 100 & 200 & 400 & 800 & 1600 & 3200 \\
\hline \multirow[t]{8}{*}{ Root colonization rate } & \multirow[t]{4}{*}{2017} & $\mathrm{WW}+\mathrm{A}$ & $56.7 \mathrm{a}$ & 56.9 a & $56.0 \mathrm{a}$ & $56.0 \mathrm{a}$ & $54.1 \mathrm{~b}$ & $51.3 \mathrm{~b}$ & $47.5 \mathrm{~b}$ \\
\hline & & WW & $21.3 \mathrm{~b}$ & $21.0 \mathrm{c}$ & $20.9 \mathrm{~b}$ & $20.7 \mathrm{~b}$ & $19.0 \mathrm{c}$ & $18.3 \mathrm{c}$ & $17.7 \mathrm{c}$ \\
\hline & & $\mathrm{WS}+\mathrm{A}$ & $58.8 \mathrm{a}$ & $58.6 \mathrm{a}$ & $58.6 \mathrm{a}$ & $58.3 \mathrm{a}$ & 56.9 a & $53.4 \mathrm{a}$ & $51.6 \mathrm{a}$ \\
\hline & & WS & $24.0 \mathrm{~b}$ & $23.9 \mathrm{~b}$ & $23.9 \mathrm{~b}$ & $23.9 \mathrm{~b}$ & $21.5 \mathrm{c}$ & $19.9 \mathrm{c}$ & $19.0 \mathrm{c}$ \\
\hline & \multirow[t]{4}{*}{2018} & $\mathrm{WW}+\mathrm{A}$ & $55.9 \mathrm{a}$ & $55.7 \mathrm{a}$ & $54.6 \mathrm{a}$ & $54.4 \mathrm{~b}$ & $52.5 \mathrm{~b}$ & $48.3 \mathrm{~b}$ & $46.1 \mathrm{~b}$ \\
\hline & & WW & $21.2 \mathrm{~b}$ & $20.9 \mathrm{~b}$ & $20.2 \mathrm{~b}$ & $20.6 \mathrm{c}$ & $19.5 \mathrm{c}$ & $17.6 \mathrm{c}$ & $17.0 \mathrm{c}$ \\
\hline & & $\mathrm{WS}+\mathrm{A}$ & $56.3 \mathrm{a}$ & $56.0 \mathrm{a}$ & $55.8 \mathrm{a}$ & $55.6 \mathrm{a}$ & $54.7 \mathrm{a}$ & $52.9 \mathrm{a}$ & $50.8 \mathrm{a}$ \\
\hline & & WS & $22.5 \mathrm{~b}$ & $21.1 \mathrm{~b}$ & $21.1 \mathrm{~b}$ & $21.1 \mathrm{c}$ & $20.2 \mathrm{c}$ & $19.0 \mathrm{c}$ & $17.9 \mathrm{c}$ \\
\hline \multirow[t]{8}{*}{ AMF hyphal length } & \multirow[t]{4}{*}{2017} & $\mathrm{WW}+\mathrm{A}$ & $12.6 \mathrm{~b}$ & $12.5 \mathrm{~b}$ & $12.4 \mathrm{~b}$ & $12.2 \mathrm{~b}$ & $11.5 \mathrm{~b}$ & $9.93 \mathrm{~b}$ & $9.43 \mathrm{~b}$ \\
\hline & & WW & $6.7 \mathrm{~d}$ & $6.36 \mathrm{~d}$ & $6.35 \mathrm{~d}$ & $6.32 \mathrm{~d}$ & $5.68 \mathrm{~d}$ & $5.48 \mathrm{~d}$ & $5.28 \mathrm{~d}$ \\
\hline & & $\mathrm{WS}+\mathrm{A}$ & $12.9 \mathrm{a}$ & $12.8 \mathrm{a}$ & $12.7 \mathrm{a}$ & $12.6 \mathrm{a}$ & $12.0 \mathrm{a}$ & $10.7 \mathrm{a}$ & $10.2 \mathrm{a}$ \\
\hline & & WS & $7.45 \mathrm{c}$ & $7.35 \mathrm{c}$ & $7.28 \mathrm{c}$ & $7.28 \mathrm{c}$ & $6.55 \mathrm{c}$ & $6.02 \mathrm{c}$ & $5.84 \mathrm{c}$ \\
\hline & \multirow[t]{4}{*}{2018} & $\mathrm{WW}+\mathrm{A}$ & $9.28 \mathrm{~b}$ & $8.94 \mathrm{a}$ & $8.83 \mathrm{~b}$ & $8.74 \mathrm{~b}$ & $8.26 \mathrm{~b}$ & $8.05 \mathrm{~b}$ & $8.00 \mathrm{a}$ \\
\hline & & WW & $6.72 \mathrm{~d}$ & $6.62 \mathrm{c}$ & $6.43 \mathrm{~d}$ & $6.34 \mathrm{~d}$ & $5.85 \mathrm{~d}$ & $5.66 \mathrm{~d}$ & $5.47 \mathrm{c}$ \\
\hline & & $\mathrm{WS}+\mathrm{A}$ & $9.67 \mathrm{a}$ & $9.00 \mathrm{a}$ & $9.20 \mathrm{a}$ & $9.10 \mathrm{a}$ & $8.60 \mathrm{a}$ & $8.30 \mathrm{a}$ & $8.10 \mathrm{a}$ \\
\hline & & WS & $7.10 \mathrm{c}$ & $7.00 \mathrm{~b}$ & $6.80 \mathrm{c}$ & $6.70 \mathrm{c}$ & $6.20 \mathrm{c}$ & $6.00 \mathrm{c}$ & $5.80 \mathrm{~b}$ \\
\hline \multirow[t]{8}{*}{$\mathrm{WUE}_{\mathrm{B}}$} & \multirow[t]{4}{*}{2017} & $\mathrm{WW}+\mathrm{A}$ & $2.92 \mathrm{a}$ & $4.20 \mathrm{a}$ & $7.67 \mathrm{a}$ & $10.8 \mathrm{~b}$ & $12.4 \mathrm{a}$ & $11.6 \mathrm{a}$ & $11.0 \mathrm{~b}$ \\
\hline & & WW & $2.25 \mathrm{~b}$ & $3.50 \mathrm{~b}$ & $6.98 \mathrm{~b}$ & $11.4 \mathrm{a}$ & $12.6 \mathrm{a}$ & $11.6 \mathrm{a}$ & $11.5 \mathrm{a}$ \\
\hline & & $\mathrm{WS}+\mathrm{A}$ & $2.28 \mathrm{~b}$ & $4.04 \mathrm{c}$ & $7.02 \mathrm{~b}$ & $9.34 \mathrm{c}$ & $10.7 \mathrm{~b}$ & $9.26 \mathrm{~b}$ & $8.91 \mathrm{c}$ \\
\hline & & WS & $2.09 \mathrm{c}$ & $3.58 \mathrm{c}$ & $6.37 \mathrm{c}$ & $8.27 \mathrm{~d}$ & $9.96 \mathrm{c}$ & $8.42 \mathrm{c}$ & $7.63 \mathrm{~d}$ \\
\hline & \multirow[t]{4}{*}{2018} & $\mathrm{WW}+\mathrm{A}$ & $3.76 \mathrm{a}$ & $5.36 \mathrm{a}$ & $9.90 \mathrm{a}$ & $12.1 \mathrm{a}$ & $14.2 \mathrm{a}$ & $13.9 \mathrm{a}$ & $13.1 \mathrm{a}$ \\
\hline & & WW & $3.35 \mathrm{~b}$ & $4.89 \mathrm{~b}$ & $9.90 \mathrm{a}$ & $12.2 \mathrm{a}$ & $14.4 \mathrm{a}$ & $13.8 \mathrm{a}$ & $12.9 \mathrm{a}$ \\
\hline & & $\mathrm{WS}+\mathrm{A}$ & $3.07 \mathrm{c}$ & $4.75 \mathrm{~b}$ & $7.96 \mathrm{~b}$ & $9.20 \mathrm{~b}$ & $9.87 \mathrm{~b}$ & $9.73 \mathrm{~b}$ & $8.58 \mathrm{~b}$ \\
\hline & & WS & $2.54 \mathrm{~d}$ & $3.81 \mathrm{c}$ & $6.53 \mathrm{c}$ & $7.36 \mathrm{c}$ & $9.20 \mathrm{c}$ & $8.33 \mathrm{c}$ & $7.17 \mathrm{c}$ \\
\hline \multirow[t]{8}{*}{$W_{Y}$} & \multirow[t]{4}{*}{2017} & $\mathrm{WW}+\mathrm{A}$ & $1.29 \mathrm{~b}$ & $2.32 \mathrm{~b}$ & $3.66 \mathrm{~b}$ & $5.84 \mathrm{ab}$ & $6.10 \mathrm{a}$ & $5.58 \mathrm{a}$ & $5.35 \mathrm{~b}$ \\
\hline & & WW & $1.29 \mathrm{~b}$ & $2.25 \mathrm{~b}$ & $3.71 \mathrm{~b}$ & $5.87 \mathrm{a}$ & $6.16 \mathrm{a}$ & $5.69 \mathrm{a}$ & $5.71 \mathrm{a}$ \\
\hline & & $\mathrm{WS}+\mathrm{A}$ & $1.38 \mathrm{a}$ & $2.54 \mathrm{a}$ & $4.52 \mathrm{a}$ & $5.62 \mathrm{~b}$ & $5.77 \mathrm{~b}$ & $5.20 \mathrm{~b}$ & $3.95 \mathrm{c}$ \\
\hline & & WS & $0.87 \mathrm{c}$ & $1.42 \mathrm{c}$ & $2.72 \mathrm{c}$ & $3.02 \mathrm{c}$ & $4.59 \mathrm{c}$ & $4.26 \mathrm{c}$ & $2.97 \mathrm{~d}$ \\
\hline & \multirow[t]{4}{*}{2018} & $\mathrm{WW}+\mathrm{A}$ & $1.67 \mathrm{a}$ & $2.55 \mathrm{a}$ & $3.93 \mathrm{a}$ & $6.19 \mathrm{a}$ & $6.05 \mathrm{a}$ & $5.56 \mathrm{a}$ & $5.30 \mathrm{a}$ \\
\hline & & WW & $1.63 \mathrm{a}$ & $2.62 \mathrm{a}$ & $3.54 \mathrm{~b}$ & $5.94 \mathrm{~b}$ & $5.98 \mathrm{a}$ & $5.51 \mathrm{ab}$ & $5.23 \mathrm{a}$ \\
\hline & & $\mathrm{WS}+\mathrm{A}$ & $1.64 \mathrm{a}$ & $2.22 \mathrm{~b}$ & $4.08 \mathrm{a}$ & $5.32 \mathrm{c}$ & $5.36 \mathrm{~b}$ & $5.23 \mathrm{~b}$ & $4.98 \mathrm{~b}$ \\
\hline & & WS & $1.12 \mathrm{~b}$ & $1.75 \mathrm{c}$ & $3.06 \mathrm{c}$ & $4.49 \mathrm{~d}$ & $4.71 \mathrm{c}$ & $4.52 \mathrm{c}$ & $4.09 \mathrm{c}$ \\
\hline
\end{tabular}

$\mathrm{WW}+\mathrm{A}$, irrigated and inoculated with AMF; WW, irrigated and non-inoculated with AMF; WS + A, non-irrigated and inoculated with AMF; WS, nonirrigated and non-inoculated with AMF. Data are presented as means of three replicates. Data with the same letter down the column within each year are not significantly different at $P<0.05$ using the Tukey test

colonization rate tended to decrease with increasing plant density, but plant density did not have a significant effect on the AMF colonization rate in the non-irrigated treatment. However, this result contradicts Eissenstat and Newman (1990), who showed that AMF colonization rate increased with the increase in plant density. This may be related to the experimental conditions such as AM fungal species and plant species. In our study, the intraspecific competition increased with increasing planting density, but the dry matter production of wheat decreased. Therefore, we conclude that the transport of photosynthetic products from the host plants to the mycorrhizal fungi was restricted as planting density increased, so that eventually the mycelial growth of mycorrhizal fungi was restricted. Moreover, in the non-irrigated treatment, the root colonization rate increased compared with well-irrigated treatments, especially at high plant densities (Table 1). These 
results agree with a previous report (Rahimzadeh and Pirzad 2017) but differ from the findings of Kohler et al. (2009) who reported that lack of irrigation significantly decreased the AMF colonization in other plants. This difference may vary according to the experimental conditions, such as AM fungal species, wheat varieties, fertilizer levels, and other factors. In addition, under drought stress root colonization rate by AM fungi remained elevated over all the treatments in the inoculated wheat plants and was positively correlated to aboveground biomass, grain yield, harvest index, and water use efficiency of wheat.

\subsection{Composition and diversity of AM fungal community of the rhizosphere soil}

The relative abundance of AMF are shown in Fig. 2. Glomeraceae (related to $F$. mosseae) was the most abundant family (93\% and $97 \%$ for $\mathrm{WW}+\mathrm{A} ; 93 \%$ and $98 \%$ for WS + $\mathrm{A} ; 70 \%$ and $66 \%$ for $\mathrm{WW} ; 77 \%$ and $74 \%$ for $\mathrm{WS}$, in 2017 and 2018 , respectively), followed by unclassified, which accounted for $3 \%, 18 \%, 2 \%$, and $9 \%$ of operational taxonomic units (OTUs) in 2017 and 3\%, 22\%, 1\%, and 12\% in 2018 for $\mathrm{WW}+\mathrm{A}, \mathrm{WW}, \mathrm{WS}+\mathrm{A}$, and WS, respectively (Fig. 2a, b). Moreover, AMF inoculation significantly increased the relative abundance of OTUs affiliated with the family Glomeraceae over two growing seasons (Fig. 2a, b), which indicated that $F$. mosseae was successfully colonized the soil. Irrigation reduced the relative abundance of Glomeraceae compared with the non-irrigated treatment when uninoculated with AMF (i.e., it decreased from 77 and 74 for WS to $70 \%$ and 66\% for WW in 2017 and 2018, respectively). In addition, other families present, although at lower relative abundances, included Paraglomeraceae (from 1.4 to $10.1 \%$ ) and Acaulosporaceae at $<1 \%$ (in most cases) over two growing seasons. It can be argued that AMF inoculation and water regimes changed the abundance of AMF. Molecular techniques demonstrated that AMF exogenous $F$. mosseae efficiently colonized the wheat rhizosphere and acted effectively on soil quality (Zhu et al. 2017).

As for the diversity of AMF community, AMF inoculation had no significant effect on the AMF richness (OTU richness) and Shannon diversity of AM fungi in both growing seasons (Fig. 2c-f). Furthermore, AMF richness and Shannon diversity were unaffected by water regimes in both growing seasons (Fig. 2c-f). These results are consistent with those obtained by Kavadia et al. (2020) and Ren et al. (2020), who demonstrated that the impact of water regime and AMF inoculation on fungal-community composition and diversity depended on soil history, soil conditions, AMF species, plant species, and plant growth stage. In our study, the soil on the Loess Plateau has poor nutritional status; thus, nutrients may be an important factor that limiting AMF richness and diversity.

\subsection{Plant biomass, grain yield, harvest index, and water use efficiency}

In order to assess the separate and combined effects of all factors on wheat production, we compared the differences in wheat grain yield, aboveground biomass, harvest index, $\mathrm{WUE}_{\mathrm{Y}}$, and $\mathrm{WUE}_{\mathrm{B}}$ at maturity in both growing seasons. Notably, the wheat grain yield, aboveground biomass, $\mathrm{WUE}_{\mathrm{B}}$, and $\mathrm{WUE}_{\mathrm{Y}}$ showed an increased trend with increasing the plant density as the plant densities increased from 50 to 800 plants $\mathrm{m}^{-2}$ and then declined in all treatments in both growing seasons (Fig. 3a-d; Table 1). In general, aboveground biomass of wheat was higher in all the treatments in 2018 than 2017 (Fig. 3c, d), due to the higher in-season rainfall in 2018 than 2017. Moreover, the irrigated treatment had significantly higher grain yield and aboveground biomass than in the non-irrigated treatment (Fig. 3a-d), showing that lack of irrigation significantly decreased wheat biomass accumulation and yield production in this rainfed environment. When compared with WS, AMF inoculation greatly improved grain yield of wheat in WS + A by $59 \pm 28 \%$ and $36 \pm 3 \%$ in 2017 and 2018, respectively (Fig. 3a, b), showing that the AMF symbiosis with plants provided benefits for dryland wheat production in this semiarid region, which agrees with previous studies (Zhang et al. 2016; Sui et al. 2019). However, AMF inoculation had different effects under well-irrigated conditions. For example, AMF inoculation increased grain yields and aboveground biomass at low plant densities (50400 ) but depressed the yields and aboveground biomass at high plant densities (800-3200) in the WW + A treatment when compared with WW, but these effects of AMF were not significantly (Fig. 3a-d). These results may due to high soil moisture reducing the role of mycorrhizas (Trejo et al. 2016; Dai et al. 2014) that meant under sufficient water conditions, plants did not need to absorb water and nutrients through mycorrhizas.

In general, harvest index tended to decrease with the increase in plant density (from $0.57 \pm 0.03$ to $0.44 \pm 0.01$ for $\mathrm{WW}+\mathrm{A}$, from $0.57 \pm 0.01$ to $0.49 \pm 0.02$ in $\mathrm{WW}$, from $0.56 \pm 0.02$ to $0.38 \pm 0.01$ for $\mathrm{WS}+\mathrm{A}$, from 0.51 \pm 0.01 to $0.36 \pm 0.01$ for WS among all the plant densities over two growing seasons). Lack of irrigation greatly decreased the harvest index of wheat but increased it when inoculated with AMF (i.e., in WS + A the harvest index increased by $10.0 \pm 3.4 \%$ in 2017 and $7.0 \pm 1.8 \%$ in 2018 compared with WS), suggesting that the presence of mycorrhizal symbionts helped the host to absorb deeper water and nutrients, thereby reducing intraspecific competition and ultimately promoting higher yields under insufficient water conditions. Rather, high plant densities greatly improved water use efficiency (i.e., in low plant densities (50-200 plants $\mathrm{m}^{-2}$ ) WUE $\mathrm{WU}_{\mathrm{B}}$ ranged from $2.09 \pm$ 0.16 to $9.90 \pm 0.78 \mathrm{~kg} \mathrm{ha}^{-1} \mathrm{~mm}^{-1}$, while in high plant 
Fig. 2 The relative abundance of arbuscular mycorrhizal fungal (AMF) families (a, b) and AMF community analysis of OTU richness $(\mathbf{c}, \mathbf{d})$ and Shannon diversity index $(\mathbf{e}, \mathbf{f})$ in wheat rhizosphere soil under different water regimes, $\mathrm{AMF}$ inoculations, and plant densities (a, c, e for 2017, b, d, f for 2018). $\mathrm{WW}+\mathrm{A}$, irrigated and inoculated with AMF; WW, irrigated and non-inoculated with AMF; WS + A, non-irrigated and inoculated with AMF; WS, non-irrigated and non-inoculated with AMF. Means $(n=3)$ with different letters indicating significant difference among treatments $(P<0.05)$.

Error bars are $+\mathrm{SE}$
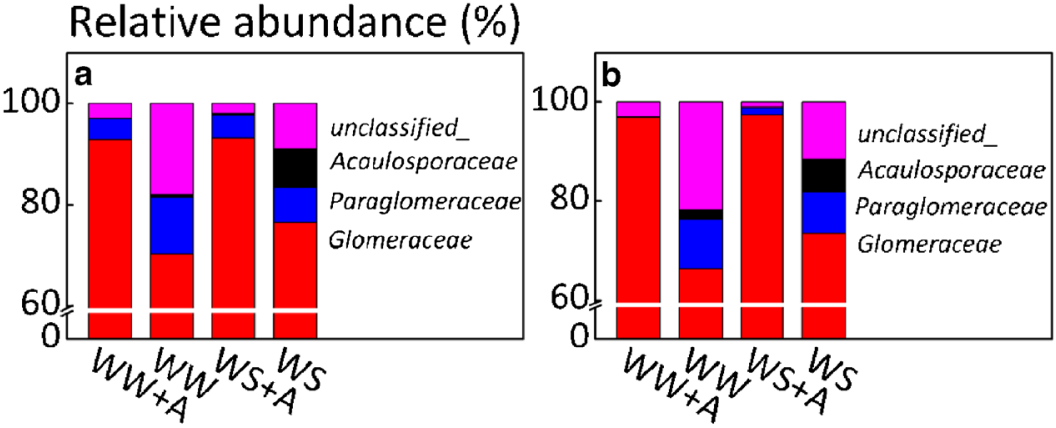

\section{OTU richness}

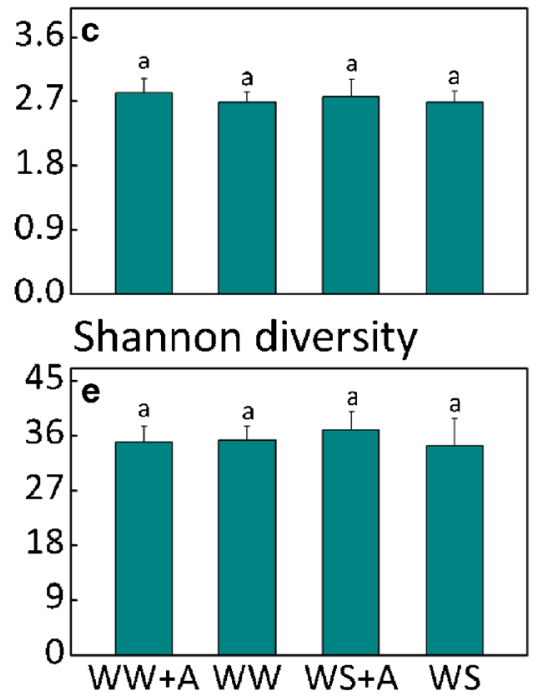

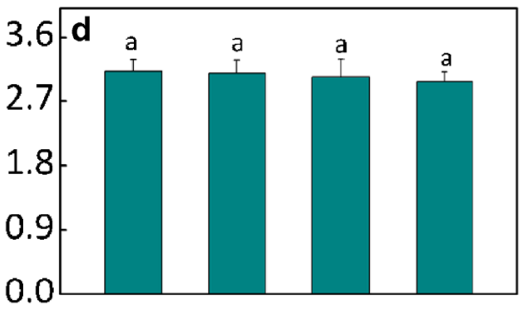

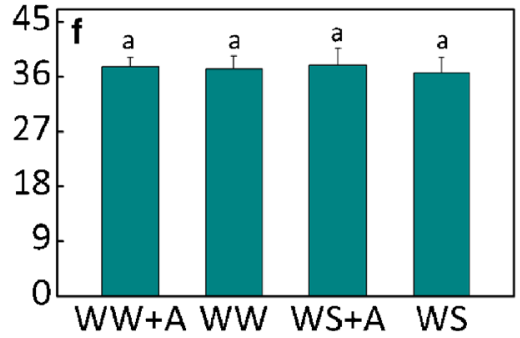

densities $\left(800-3200\right.$ plants $\left.\mathrm{m}^{-2}\right)$, it ranged from $7.17 \pm$ 0.59 to $14.4 \pm 0.65 \mathrm{~kg} \mathrm{ha}^{-1} \mathrm{~mm}^{-1}$ (Table 1)). Moreover, irrigation significantly increased the wheat water use efficiency compared with the non-irrigated treatment in both years (Table 1); these differences were mainly the result of improved grain yields and biomass accumulation of the crop, because the increment of water consumption is lower than the increment of production in the irrigation treatment. $W_{U} E_{B}$ and $W_{U} E_{Y}$ were notably increased when inoculated with AMF under non-irrigated conditions compared with WW treatments (i.e., $\mathrm{WUE}_{\mathrm{Y}}$ increased by 53.0 $\pm 26.1 \%$ and $25.1 \pm 11.5 \%$, respectively in 2017 and 2018), in which Zhang et al. (2016) attributed to the symbiosis of AMF with wheat improving the water uptake, water use efficiency, and phosphorus uptake of the wheat by the external hyphae of AMF. However, in most cases, mycorrhizal inoculation had no significant effect on the aboveground weight, grain yield, or harvest index at high plant densities in the well-irrigated treatment compared with non-mycorrhizal inoculation treatments, except at some low plant densities (Fig. 3; Table 1), which is in agreement with previous studies (West 1996; Trejo et al. 2016). This may be attributed to the negative interaction between plants without abiotic stress (West 1996) and AMF forming a mycelium network structure among plants that enhanced the intraspecific competition and reduced the amount of carbon available for growth in host plants unable to adjust their carbon assimilation rate to match the increased demand created by the AMF sink, especially with the increasing plant density. These results showed that under insufficient water conditions, AMF inoculation enhanced crop drought tolerance, increased the water use efficiency and harvest index, and finally improved crop productivity.

To sum up, with the increase in plant density, the positive effect of AMF inoculation on plant productivity and water use efficiency decreased (Fig. 3; Table 1). Similarly, in the wellirrigated treatment, AMF inoculation had a little positive effect on plant productivity and water use efficiency at low plant densities, but had no significant effect at high plant densities (Fig. 3; Table 1). The different effects of AMF at different plant densities can be attributed to the increase of light competition between plants and the decrease in photosynthetic capacity as plant density increases. This suggests that photosynthetic products were a more important limiting factor for host plants than soil water and nutrients especially in well- 
Fig. 3 Grain yield (a, b), aboveground biomass (c, $\mathbf{d})$, and harvest index (e, f) of wheat at maturity in two growing seasons under different water regimes, AMF inoculations, and plant densities (a, c, e for 2017, b, d, f for 2018). WW + A, irrigated and inoculated with AMF; WW, irrigated and non-inoculated with AMF; WS + A, non-irrigated and inoculated with AMF; WS, nonirrigated and non-inoculated with AMF. Data are presented as means $\pm \mathrm{SE}$ of three replicates. Significant differences among irrigation and AMF inoculation treatments are denoted by asterisks (Tukey test): $* P<0.05$; $* * P<0.01$; *** $P<0.001$; NS, not significant
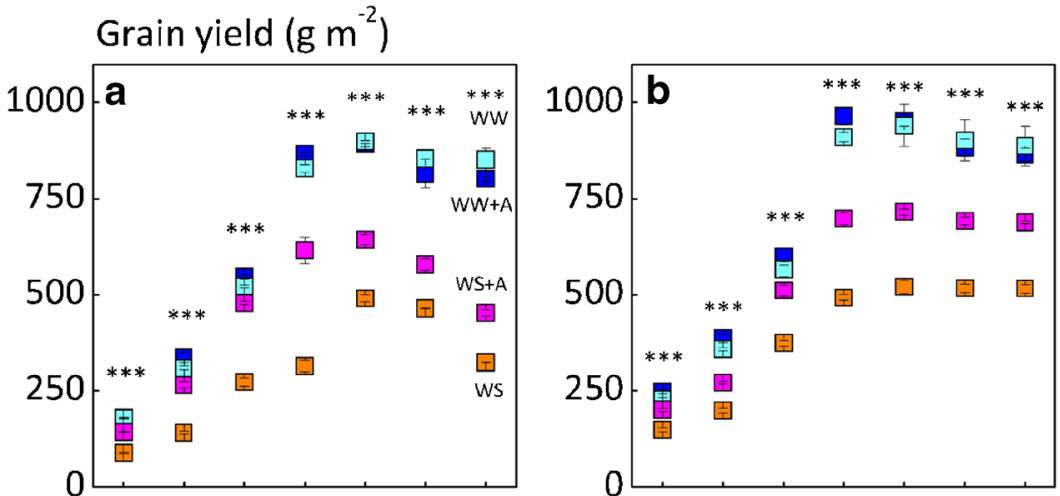

Aboveground biomass $\left(\mathrm{g} \mathrm{m}^{-2}\right)$
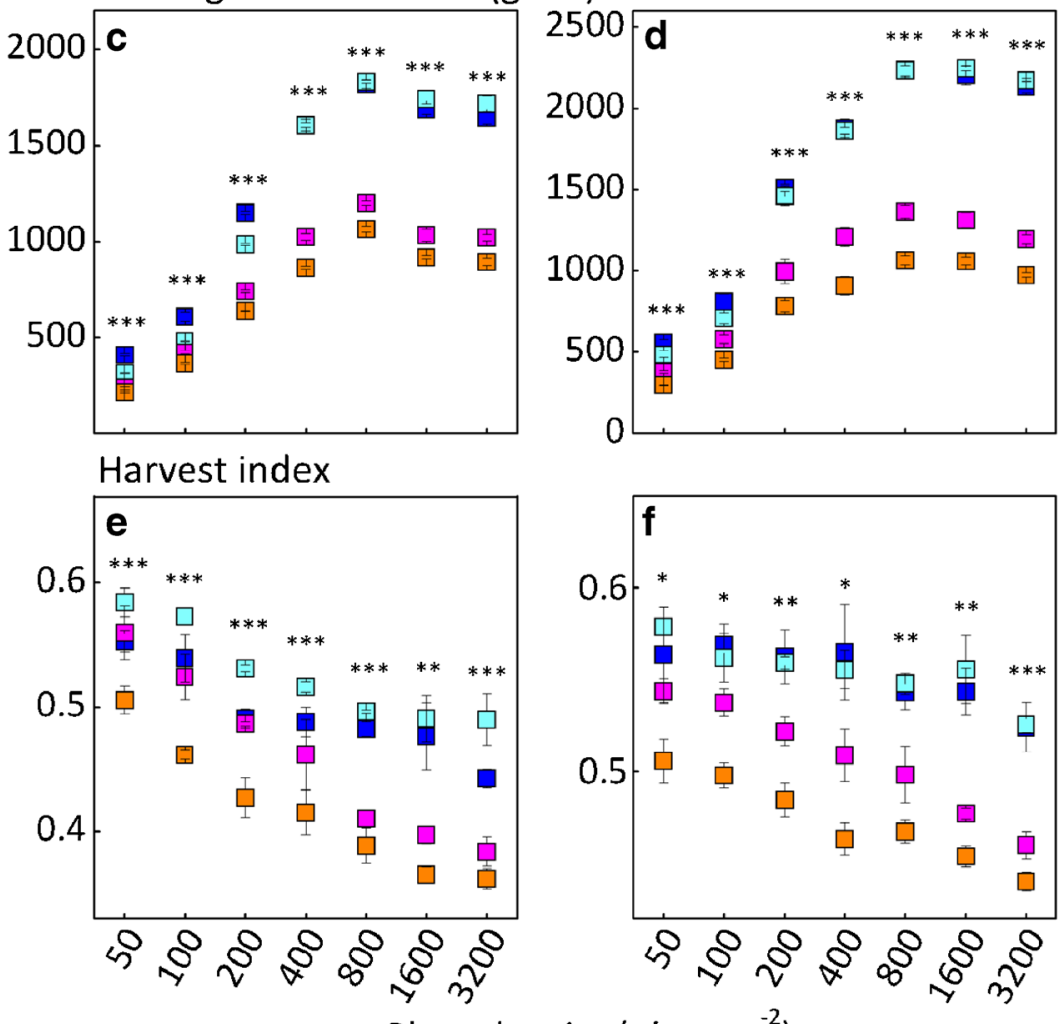

Plant density (plant $\mathrm{m}^{-2}$ ) irrigated conditions, so that the mycorrhizae became less important for host plants and their effect decreases as the plant density increases.

\subsection{Rhizosphere soil carbon and nitrogen}

The SOC content and the ratio of SOC to TN are important indicators for assessing soil fertility (Koch et al. 2004). AMF are major agents directing carbon into the soil by moving nutrients from the soil into plant roots in exchange for photoassimilates (Johnson et al. 2013). In the present study, we found that the SOC content and SOC to TN ratio increased with increasing plant density to a peak at 800 plants $\mathrm{m}^{-2}$ and then decreased with the plant densities increase (but not significantly) in both growing seasons (Fig. 4a-f). Aboveground biomass and grain yield showed a similar trend (Fig. 3a-d). We suggest that this may be because at low plant densities, wheat fixed less energy by photosynthesis per unit areas, so less organic matter was transported to the soil, while at high plant densities, the stronger intraspecific competition among plants led to decreased of biomass accumulation, which in turn led to a decrease of the SOC and SOC to TN ratio. In general, there was no significant difference in rhizosphere SOC content among $\mathrm{WW}+\mathrm{A}, \mathrm{WW}$, and $\mathrm{WS}+\mathrm{A}$ treatments, but they were all significantly higher than that in WS treatment in both growing seasons (Fig. 4a, b), indicating that 
irrigation and AMF inoculation had positive effects on rhizosphere SOC, which is consistent with previous studies (Song et al. 2020; Zhu et al. 2017; Zhou et al. 2020). A possible explanation for this result is that AMF symbiosis and irrigation increase carbon sequestration in soil not only by increasing root carbon inputs but also by lowering native soil organic matter decomposition and rhizosphere priming effects (Zhou et al. 2020). It may be due to AMF inoculation increasing the relative abundance of Glomeraceae (Fig. 2a, b) that have a higher ability to produce soil extra-matrical hyphal length (Voets et al. 2006). As mentioned above, in our study AMF inoculation significantly increased soil extra-matrical hyphal length (Table 1), which are critically beneficial in increasing soil carbon fractions (Ren et al. 2020).

By contrast, the TN content of the soil differed with the growing season and treatment (Fig. 4c, d). Contrary to plant biomass, increasing plant density induced a significant decrease in TN over two growing seasons, demonstrating that crop growth is a process of soil nitrogen consumption, and greater biomass accumulation leading to more uptake of TN (Fig. 4c, d). In most cases, in 2017 there was no significant difference in TN content of the soil among the treatments at the same plant density, but in 2018 , the TN content in non-irrigated treatment was significantly higher than that in the irrigated treatment (Fig. 4c, d), which
Fig. 4 Soil organic carbon (SOC; $\mathbf{a}, \mathbf{b})$, total nitrogen (TN; c, d), and the ratio of SOC to TN (SOC/ $\mathrm{TN} ; \mathbf{e}, \mathbf{f})$ in wheat rhizosphere soil in two growing seasons under different water regimes, AMF inoculations, and plant densities (a, c, e for 2017, b, d, f for 2018) $\mathrm{WW}+\mathrm{A}$, irrigated and inoculated with AMF; WW, irrigated and non-inoculated with AMF; WS + A, non-irrigated and inoculated with AMF; WS, non-irrigated and non-inoculated with AMF. Data are presented as means $\pm \mathrm{SE}$ of three replicates. Significant differences among irrigation and AMF inoculation treatments are denoted by asterisks (Tukey test): $* P<0.05 ; * * P<0.01$; $* * * P<0.001$; NS, not significant
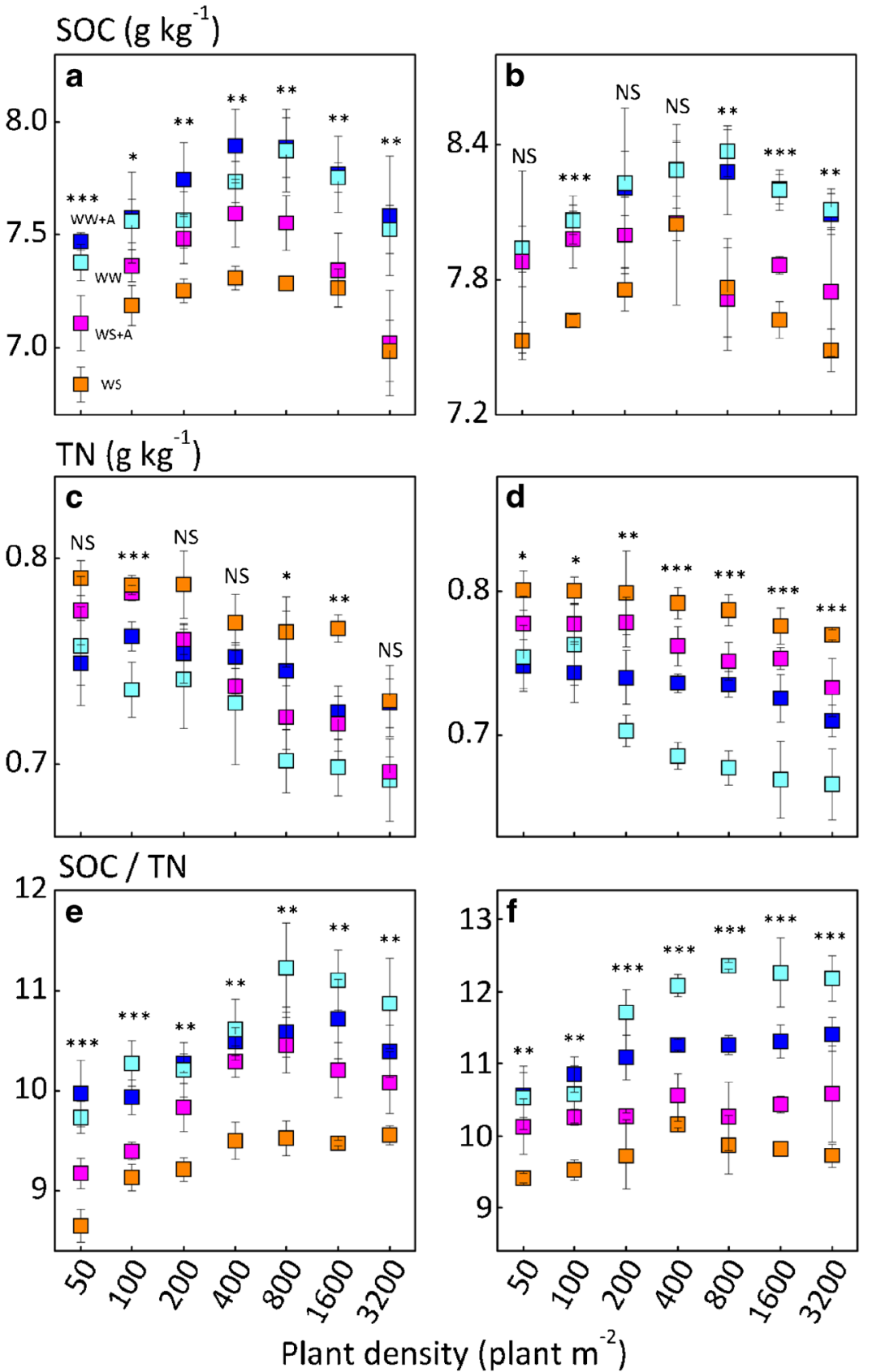
Fig. 5 Soil microbial biomass carbon (MBC) (a, b), microbial biomass nitrogen (MBN) (c, d), and the ratio of $\mathrm{MBC}$ to $\mathrm{MBN}$ $(\mathrm{MBC} / \mathrm{MBN})(\mathbf{e}, \mathbf{f})$ in wheat rhizosphere soil in two growing seasons under different water regimes, $\mathrm{AMF}$ inoculations, and plant densities (a, c, e for 2017, b, d, f for 2018). WW + A, irrigated and inoculated with AMF; WW, irrigated and non-inoculated with $\mathrm{AMF} ; \mathrm{WS}+\mathrm{A}$, non-irrigated and inoculated with AMF; WS, nonirrigated and non-inoculated with AMF. Data are presented as mean \pm SE of three replicates.

Significant differences among irrigation and AMF inoculation treatments are denoted by asterisks (Tukey test): $* P<0.05$; $* * P<0.01 ; * * * P<0.001 ; \mathrm{NS}$, not significant
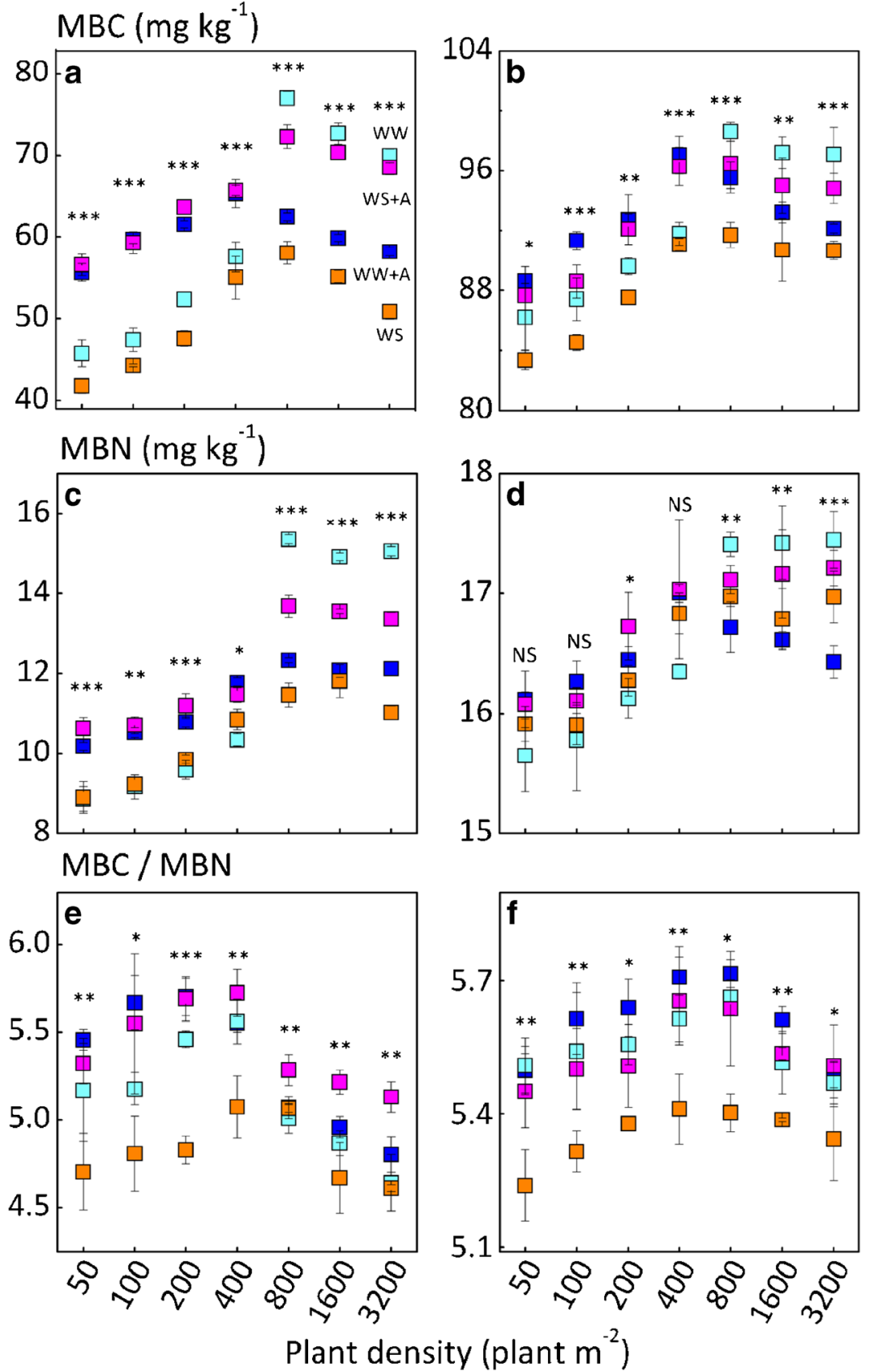

might be the result of the change in soil microbial activity due to the difference in rainfall between two growing seasons. Our data showed that AMF inoculation decreased the TN content in the non-irrigated treatment (Fig. 4b, c), which was consistent with recent research (Ren et al. 2020) that demonstrated that AMF inoculation decreased soil TN as a result of AMF stimulation of plant growth and higher uptake of mineral nitrogen by the crop. However, in most cases, the TN content increased in the irrigated treatment (Fig. 4c, d), which may be attributed to the AMF inoculation enhancing the plant intraspecific competitive strength which decreased the biomass and yield accumulation under irrigated conditions.

\subsection{Rhizosphere soil microbial biomass carbon and nitrogen}

The rhizosphere soil MBC, MBN, and $\mathrm{MBC}$ to $\mathrm{MBN}$ ratio over two growing seasons are shown in Fig. 5. Soil MBC, $\mathrm{MBN}$, and MBC to MBN ratio increased as plant densities increased from 50 to 800 plant $\mathrm{m}^{-2}$ and then decreased with the further increase in plant density. AMF inoculation increased soil $\mathrm{MBC}, \mathrm{MBN}$, and $\mathrm{MBC}$ to $\mathrm{MBN}$ ratio compared with non-AMF inoculation treatment as plant densities increased from 50 to 800 plant $\mathrm{m}^{-2}$, but when plant densities increased higher than $800 \mathrm{~m}^{-2}$, AMF inoculation had neutral 
or negative effects on soil MBC, MBN, and the MBC to MBN ratio in the $\mathrm{WW}+\mathrm{A}$ treatment (Fig. 5). In general, the contents of $\mathrm{MBC}, \mathrm{MBN}$, and $\mathrm{MBC}$ to $\mathrm{MBN}$ ratio under wellirrigated conditions were more than that in non-irrigated conditions, regardless of AMF inoculation.

Soil microbial biomass is the active component of soil organic matter and the source of available nutrients, involved in regulating soil mineralization and material energy flow, and can be used as an indicator of soil biological function and soil fertility (Hargreaves et al. 2003). Compared with other soil nutrient indicators, soil microbial biomass carbon and nitrogen could reflect soil quality changes more sensitively and more convincingly. Our results reveal that AMF inoculation significantly improved the values of MBC, MBN, and MBC to $\mathrm{MBN}$ ratio both in the non-irrigated and irrigated treatment (at low plant densities) (Fig. 5). One explanation for this could be that AMF inoculation improved the soil microbial activity (Pellegrino et al. 2012). In addition, the content of MBC and MBN in 2018 was higher than that in 2017 (Fig. 5a-d), possibly because the rainfall in 2018 was more than that in 2017 , providing a better soil water content and a more comfortable environment for the growth of soil microorganisms, and then the addition of long-term AMF increased the microbial biomass and changed the microbial community composition.

\section{Conclusions}

For the first time, dual density- and moisture-dependent effects of AMF on crop productivity and soil quality were tested in a semiarid agricultural region. We found that exogenous AMF inoculation could modify the AMF community composition, but had no effect on the native diversity of the AMF community. Our results demonstrated that the beneficial AMF microorganisms had a major effect on improving host growth, productivity, and soil quality under dryland (non-irrigated) conditions. However, under irrigated condition, AMF inoculation had no significant effect on crop productivity and soil quality at high plant densities, whereas it slightly improved crop productivity and soil quality at low planting densities. Moreover, we found that the effects of AMF on crop productivity and soil quality were contingent on water availability and plant density, suggesting that effects of water relations and intraspecific competition on crop growth had an impact on AMF responses. Therefore, our results may offer some directions for future sustainable agricultural development and soil degradation management in the semiarid Loess Plateau region.

Acknowledgments The authors thank Professor Neil C. Turner for correcting the English and providing some critical comments and suggestions.

\section{Compliance with ethical standards}

Funding This work was funded by the Natural Science Foundation of China (31570415), National Specialized Support Plan for Outstanding Talents ("Ten Thousand People Plan"), and the Fundamental Research Funds for the Central Universities (561220012).

Conflict of interest The authors declare that they have no conflict of interest.

Authors' contributions Conceptualization, Y.C.X. and H.X.D.; methodology, H.X.D. and C.L.L.; data curation, Y.C.X., H.X.D., and C.L.L.; investigation, H.X.D., C.L.L., J.Y.L, and B.Z.W.; writing (original draft), H.X.D.; writing (review and editing), Y.C.X., H.X.D., M.N., and C.L.L.; funding acquisition, Y.C.X. and H.X.D.; resources, Y.C.X. and H.X.D.; supervision, Y.C.X. and H.X.D. All authors were involved in the revision of the draft manuscript and have approved the final content.

Data availability The datasets analyzed during the current study are available from the corresponding author on reasonable request.

Ethics approval Not applicable.

Consent to participate Not applicable.

Consent for publication All the authors whose names appeared on the submission approved the version to be published and agreed to be accountable for all aspects of the work in ensuring that the questions related to the accuracy of integrity of any part of the work were appropriately investigated and resolved.

Code availability Not applicable.

\section{References}

Bedini S, Pellegrino E, Avio L, Pellegrini S, Bazzoffi P, Argese E, Giovannetti M (2009) Changes in soil aggregation and glomalinrelated soil protein content as affected by the arbuscular mycorrhizal fungal species Glomus mosseae and Glomus intraradices. Soil Biol Biochem 41:1491-1496. https://doi.org/10.1016/j.soilbio.2009.04.005

Brookes PC, Landman A, Pruden G, Jenkinson DS (1985) Chloroform fumigation and the release of soil nitrogen: a rapid direct extraction method to measure microbial biomass nitrogen in soil. Soil Biol Biochem 17:837-842. https://doi.org/10.1016/0038-0717(85) 90144-0

Crouzet O, Poly F, Bonnemoy F, Bru D, Batisson I, Bohatier J, Philippot L, Mallet C (2016) Functional and structural responses of soil Ncycling microbial communities to the herbicide mesotrione: a doseeffect microcosm approach. Environ Sci Pollut R 23:1-11. https:// doi.org/10.1007/s11356-015-4797-8

Dai M, Hamel C, Bainard LD, Arnaud MS, Grant CA, Lupwayi NZ, Malhi SS, Lemke R (2014) Negative and positive contributions of arbuscular mycorrhizal fungal taxa to wheat production and nutrient uptake efficiency in organic and conventional systems in the Canadian prairie. Soil Biol Biochem 74:156-166. https://doi.org/ 10.1016/j.soilbio.2014.03.016

Eissenstat DM, Newman EI (1990) Seedling establishment near large plants: effects of vesicular-arbuscular mycorrhizas on the intensity 
of plant competition. Funct Ecol 4:95-99. https://doi.org/10.2307/ 2389658

Farooq M, Siddique KHM (2016) Research and developmental issues in dryland agriculture. In: Farooq M, Siddique KHM (eds) Innovations in dryland agriculture. Springer International Publishing, Cham, pp $31-46$

Giovannetti M, Mosse B (1980) An evaluation of techniques for measuring vesicular-arbuscular infection in roots. New Phytol 84:489-500. https://doi.org/10.1111/j.1469-8137.1980.tb04556.x

Graham JH, Abbott LK (2000) Wheat responses to aggressive and nonaggressive arbuscular mycorrhizal fungi. Plant Soil 220:207-218. https://doi.org/10.1023/A:1004709209009

Hargreaves PR, Brookes PC, Ross GJS, Poulton PR (2003) Evaluating soil microbial biomass carbon as an indicator of long-term environmental change. Soil Biol Biochem 35:401-407. https://doi.org/10. 1016/S0038-0717(02)00291-2

Jakobsen I, Abbott LK, Robson AD (1992) External hyphae of vesicular arbuscular mycorrhizal fungi associated with Trifolium subterraneum L. New Phytol 120:371-380. https://doi.org/10. 1111/j.1469-8137.1992.tb01077.x

Johnson NC, Angelard C, Sanders IR, Kiers ET (2013) Predicting community and ecosystem outcomes of mycorrhizal responses to global change. Ecol Lett 16:140-153. https://doi.org/10.1111/ele.12085

Kahmen A, Perner J, Buchmann N (2015) Diversity-dependent productivity in semi-natural grasslands following climate perturbations. Funct Ecol 19:594-601. https://doi.org/10.1111/j.1365-2435.2005.01001.x

Kavadia A, Omirou M, Fasoula D, Trajanoski S, Andreou E, Ioannides TM (2020) Genotype and soil water availability shape the composition of AMF communities at chickpea early growth stages. Appl Soil Ecol 150:103443. https://doi.org/10.1016/j.apsoil.2019.103443

Koch AM, Kuhn G, Fontanillas P, Fumagalli L, Goudet J, Sanders IR (2004) High genetic variability and low local diversity in a population of arbuscular mycorrhizal fungi. Proc Natl Acad Sci U S A 101: 2369-2374. https://doi.org/10.1073/pnas.0306441101

Kohler J, Caravaca F, Alguacil MD, Roldan A (2009) Elevated $\mathrm{CO}_{2}$ increases the effect of an arbuscular mycorrhizal fungus and a plantgrowth-promoting rhizobacterium on structural stability of a semiarid agricultural soil under drought conditions. Soil Biol Biochem 41: 1710-1716. https://doi.org/10.1016/j.soilbio.2009.05.014

Mo F, Han J, Wen XX, Wang XK, Li PF, Vinay N, Jia ZK, Xiong YC, Liao YC (2020) Quantifying regional effects of plastic mulch on soil nitrogen pools, cycles, and fluxes in rain-fed agro-ecosystems of the Loess Plateau. Land Degrad Dev 1:1-13. https://doi.org/10.1002/ 1dr.3548

Pellegrino E, Turrini A, Gamper HA, Cafà G, Bonari E, Young JPW, Giovannetti M (2012) Establishment, persistence and effectiveness of arbuscular mycorrhizal fungal inoculants in the field revealed using molecular genetic tracing and measurement of yield components. New Phytol 194:810-822. https://doi.org/10.1111/j.1469-8137.2012.04090.x

Rahimzadeh S, Pirzad A (2017) Arbuscular mycorrhizal fungi and Pseudomonas in reduce drought stress damage in flax (Linum usitatissimum L.): a field study. Mycorrhiza 27:537-552. https:// doi.org/10.1007/s00572-017-0775-y

Ren AT, Mickan BS, Li JY, Zhou R, Zhang XC, Ma MS, Wesly K, Xiong YC (2020) Soil labile organic carbon sequestration is tightly correlated with the abundance and diversity of arbuscular mycorrhizal fungi in semiarid maize field. Land Degrad Dev. https://doi.org/ 10.1002/ldr.3773

Shukla N, Awasthi RP, Rawat L, Kumar J (2012) Biochemical and physiological responses of rice (Oryza sativa L.) as influenced by Trichoderma harzianum under drought stress. Plant Physiol Biochem 54:78-88. https://doi.org/10.1016/j.plaphy.2012.02.001

Song XL, Wu PT, Gao XD, Yao J, Zou YF, Zhao XN, Siddique KHM, Hu W (2020) Rainwater collection and infiltration (RWCI) systems promote deep soil water and organic carbon restoration in waterlimited sloping. Agr Water Manage 242:106400. https://doi.org/ 10.1016/j.agwat.2020.106400

Sui X, Zhang T, Tian Y, Xue R, Li A (2019) A neglected alliance in battles against parasitic plants: arbuscular mycorrhizal and rhizobial symbioses alleviate damage to a legume host by root hemiparasitic Pedicularis species. New Phytol 221:470-481. https://doi.org/10. 1111/nph.15379

Thirkell TJ, Charters MD, Elliott AJ, Sait SM, Field KJ (2017) Are mycorrhizal fungi our sustainable saviours? Considerations for achieving food security. J Ecol 105(4):921-929. https://doi.org/10. $1111 / 1365-2745.12788$

Trejo D, Barois I, Sangabriel-Conde W (2016) Disturbance and land use effect on functional diversity of the arbuscular mycorrhizal fungi. Agrofor Syst 90:265-279. https://doi.org/10.1007/s10457-015-9852-4

Voets L, De La Providencia IE, Declerck S (2006) Glomeraceae and Gigasporaceae differ in their ability to form hyphal networks. New Phytol 172:185-188. https://doi.org/10.1111/j.1469-8137. 2006.01873.x

West GB (1996) A general model for the origin of allometric scaling laws in biology. Science 276:122-126. https://doi.org/10.1126/science. 276.5309 .122

Wezel A, Casagrande M, Celette F, Vian JF, Ferrer A, Peigné J (2014) Agroecological practices for sustainable agriculture. A review. Agron Sustain Dev 34:1-20. https://doi.org/10.1007/s13593-013-0180-7

Wezel A, Soldat V (2009) A quantitative and qualitative historical analysis of the scientific discipline of agroecology. Int J Agric Sustain 7: 3-18. https://doi.org/10.3763/ijas.2009.0400

Zhang Q, Wu JJ, Yang F, Lei Y, Zhang QF, Cheng XL (2016) Alterations in soil microbial community composition and biomass following agricultural land use change. Sci Rep-UK 6:36587. https://doi.org/ $10.1038 /$ srep36587

Zhou J, Zang HD, Loeppmann S, Gube M, Kuzyakov Y, Pausch J (2020) Arbuscular mycorrhiza enhances rhizodeposition and reduces the rhizosphere priming effect on the decomposition of soil organic matter. Soil Biol Biochem 140:107641. https://doi.org/10.1016/j. soilbio.2019.107641

Zhu Y, Lv GC, Chen YL, Gong XF, Peng YN, Wang ZY, Ren AT, Xiong YC (2017) Inoculation of arbuscular mycorrhizal fungi with plastic mulching in rainfed wheat: a promising farming strategy. Field Crop Res 204:229-241. https://doi.org/10.1016/j.fcr.2016.11.005

Publisher's note Springer Nature remains neutral with regard to jurisdictional claims in published maps and institutional affiliations. 